\title{
High mitochondrial diversity within and among populations of Malagasy poison frogs
}

\author{
Miguel Vences, ${ }^{\mathrm{a}, *}$ Ylenia Chiari, ${ }^{\mathrm{b}}$ Liliane Raharivololoniaina, ${ }^{\mathrm{c}}$ and Axel Meyer ${ }^{\mathrm{b}}$ \\ ${ }^{a}$ Institute for Biodiversity and Ecosystem Dynamics, Zoological Museum, University of Amsterdam, P.O. Box 94766, \\ Amsterdam 1090 GT, The Netherlands \\ ${ }^{\mathrm{b}}$ Department of Biology (Evolutionary Biology), University of Konstanz, Constance 78457, Germany \\ c Département de Biologie Animale, Université d'Antananarivo, Antananarivo 101, Madagascar
}

Received 17 January 2003; revised 12 May 2003

\begin{abstract}
The diurnal, brightly colored, and toxic frogs of the genus Mantella are among the most prominent representatives of the endemic anuran fauna of Madagascar. Especially three closely related species, M. aurantiaca, M. crocea, and M. milotympanum, are intensively collected for the pet trade, although basic data on their natural history and genetic diversity are still lacking. Our phylogenetic analyses based on $2.8 \mathrm{kbp}$ of partial $16 \mathrm{~S}$ rRNA, 12S rRNA, cytochrome $b$, and rhodopsin DNA sequences confirmed that these species belong to one of the five major clades in Mantella, the M. madagascariensis group. A haplotype network constructed using $830 \mathrm{bp}$ of cytochrome $b$ in 49 individuals from seven populations revealed that M. milotympanum and M. crocea have largely similar haplotypes sharing, confirming doubts about the species validity of $M$. milotympanum and indicating independent evolution of bright orange pattern in $M$. milotympanum and $M$. aurantiaca. Further, clustering of four individuals of $M$. aurantiaca from Andranomena with $M$. crocea suggests incomplete lineage sorting or introgression resulting from secondary contact of refugial populations. AMOVA confirmed significant intrapopulation nucleotide diversity $(>20 \%)$. These diversity patterns and our field observations indicate relatively large population sizes. Hence, overcollecting is probably a minor problem and conservation efforts should rather focus on saving some large populations from habitat destruction through logging and forest fires.
\end{abstract}

(C) 2003 Published by Elsevier Inc.

Keywords: Amphibia; Mantellidae; Mantella; Phylogeny; Conservation; Population differentiation; Color pattern; 16S rRNA; 12S rRNA; Cytochrome $b$; Rhodopsin

\section{Introduction}

Madagascar's biotas are characterised by extremely high levels of endemism and a high species diversity. The almost 200 nominal species of Malagasy amphibians currently recognised show a degree of endemism greater than $99 \%$ (Glaw and Vences, 2000). Because the rates of habitat destruction in Madagascar are alarming (Green and Sussman, 1990), the region has been classified as one of the most important 'hotspots' for conservation of biodiversity (Myers et al., 2000). Malagasy frogs belong to a number of endemic clades. The most species-rich of

\footnotetext{
${ }^{*}$ Corresponding author. Fax: +31-20-525-7238.

E-mail address: vences@science.uva.nl (M. Vences).
}

these is the family Mantellidae, which currently contains about 130 species.

Malagasy poison frogs, classified as genus Mantella in the Mantellidae, thus far comprise 17 species of diurnal, terrestrial frogs of mostly aposematic coloration (Vences et al., 1999). Similar to several other groups of aposematic frogs, Mantella are characterised by toxic skin alkaloids (Daly et al., 1996), which probably accumulate through the uptake of arthropod prey (Daly et al., 1997). In conjunction with morphological features related to the feeding mechanism, and complex mating strategies and behaviour, these features imply a remarkable case of convergence with the poison-dart frogs (Dendrobatidae) of South and Central America (Caldwell, 1996; Summers and Clough, 2001; Vences et al., 1998a). Such unusual characteristics have resulted in 
Mantella being highly priced by hobbyists, particularly the more brilliantly colored species, such that large numbers of specimens are exported from Madagascar every year (Behra, 1993). In a concerted effort to monitor the trade, all Mantella species have been placed on Appendix II of the Convention on International Trade in Endangered Species of Wild Fauna and Flora (CITES). Some species (M. aurantiaca, M. crocea, $M$. bernhardi, M. cowani, $M$. viridis, and $M$. expectata) are considered to merit high conservation priority (Raxworthy and Nussbaum, 2000; Vences et al., 1999), mainly because of their limited distribution areas (for distribution maps, see Vences et al., 1999). Malagasy amphibians are known to be vulnerable to forest fragmentation (Vallan, 2000, 2002) although data for Mantella are so far lacking.

To determine conservation priorities and effectively manage an endangered taxon, it is important to understand the taxonomy and evolutionary history of the group to which it belongs. Although several Mantella species are easily distinguished based on their coloration patterns, previous studies on osteology (Vences et al., 1998b), allozymes (Vences et al., 1998c), and karyological data (Odierna et al., 2001; Pintak et al., 1998) have either produced conflicting phylogenetic results or an unsatisfactory level of resolution. This is particularly true of the Golden Mantella (Mantella aurantiaca), which is the most distinctive representative of its genus, and a well-established flagship species for habitat conservation in central eastern Madagascar (Zimmermann, 1996). Even now, only the Torotorofotsy swamp and its surroundings have been been reliably reported as locality for this species, and its relationships to other species remain unclear. Allozyme data (Vences et al., 1998c) and analysis of mitochondrial 16S rRNA sequences (Schaefer et al., 2002) suggest that $M$. aurantiaca forms a well-corroborated clade with four other species, M. crocea, M. milotympanum, M. madagascariensis, and $M$. pulchra, but conflicting results were obtained on the relationships within this clade which was named the M. madagascariensis group (Schaefer et al., 2002). This group is characterised by a high diversity in color phenotypes exemplified by the black and yellow $M$. madagascariensis, the uniformly golden-orange $M$. aurantiaca, and the more cryptic $M$. crocea.

The goal of this study was to contribute to the knowledge on phylogenetic relationships of, and phylogeography within, the species of the M. madagascariensis group. To this end, we produced a highly resolved phylogeny for 15 Mantella species based on $2.8 \mathrm{kbp}$ of mitochondrial and nuclear genes. In addition, we examined haplotype variation in the cytochrome $b$ gene both among and within seven populations of the group, encompassing the complete known distribution area of $M$. aurantiaca, $M$. crocea, and $M$. milotympanum. We discuss these data not only to provide a framework on which to base future conservation efforts, but also to further our understanding of speciation processes and character evolution in aposematic amphibians.

\section{Materials and methods}

\subsection{Sampling localities and methods}

Specimens from 15 species comprising 5 species groups (as defined in Schaefer et al., 2002), including the Mantella betsileo group (M. betsileo, M. aff. betsileo, $M$. expectata, and $M$. viridis), the $M$. cowani group ( $M$. cowani, M. nigricans, M. haraldmeieri, and M. baroni), the M. madagascariensis group (M. aurantiaca, M. crocea, M. milotympanum, M. madagascariensis, and $M$. pulchra), the $M$. bernhardi group (M. bernhardi), and the $M$. laevigata group ( $M$. laevigata), were available from previous studies (Schaefer et al., 2002; Vences et al., 1998c). The family Mantellidae contains five genera (Aglyptodactylus, Boophis, Laliostoma, Mantella, and Mantidactylus), all of which are endemic to the Malagasy region (Vences and Glaw, 2001). Mantella is known to be nested within the paraphyletic Mantidactylus and species of the subgenus Blommersia are the sister group of Mantella (Schaefer et al., 2002). One of these Blommersia species, Mantidactylus wittei, was used as the outgroup in our study.

Fieldwork was carried out in December 2001 during which six populations were sampled and geographical coordinates and the altitude above sea level were recorded using GPS instruments: (1) Sahamarolambo forest, south of Fierenana ( $M$. milotympanum), $18^{\circ} 32^{\prime} 36^{\prime \prime} \mathrm{E}, 48^{\circ} 26^{\prime} 56^{\prime \prime} \mathrm{S}$; $948 \mathrm{~m}$; (2) Ihofa, west of Mantadia National Park (M. crocea), $18^{\circ} 46^{\prime} 06^{\prime \prime} \mathrm{S}$, $48^{\circ} 22^{\prime} 18^{\prime \prime} \mathrm{E}$; $1017 \mathrm{~m}$; (3) forest east of Ambohimanarivo (M. crocea), $18^{\circ} 48^{\prime} 34^{\prime \prime} \mathrm{S}, 48^{\circ} 16^{\prime} 52^{\prime \prime} \mathrm{E}$; $1057 \mathrm{~m}$; (4) Torotorofotsy, swamp site 1 (M. aurantiaca), $18^{\circ} 52^{\prime} 29^{\prime \prime} \mathrm{S}$, $48^{\circ} 22^{\prime} 21^{\prime \prime} \mathrm{E}$; $960 \mathrm{~m}$; (5) Torotorofotsy, swamp site 2, north of Maromitsinjo (M. aurantiaca), $18^{\circ} 51^{\prime} 19^{\prime \prime} \mathrm{S}$, $48^{\circ} 21^{\prime} 36^{\prime \prime} \mathrm{E}$; $950 \mathrm{~m}$; and (6) Andromena forest at Samarirana river $\left(M\right.$. aurantiaca) $, 1^{\circ} 01.5^{\prime} \mathrm{S}, 48^{\circ} 10.0^{\prime} \mathrm{E}$; $921 \mathrm{~m}$. These localities extend along a north-south stretch of ca. $70 \mathrm{~km}$ in central eastern Madagascar (Fig. 1) that encompasses the complete distribution areas of all three species. No other localities of these species are reliably known at present.

All specimens captured could be unambiguously identified using the determination key of Vences et al. (1999). From each population, 7-40 Mantella individuals were collected, their sex and snout-vent length recorded, and released after clipping off 1-2 toes of each specimen. Samples of $M$. madagascariensis were obtained from the pet trade in Madagascar; all were collected in the Marolambo region on the same day by the same local collector, and therefore were likely to origi- 


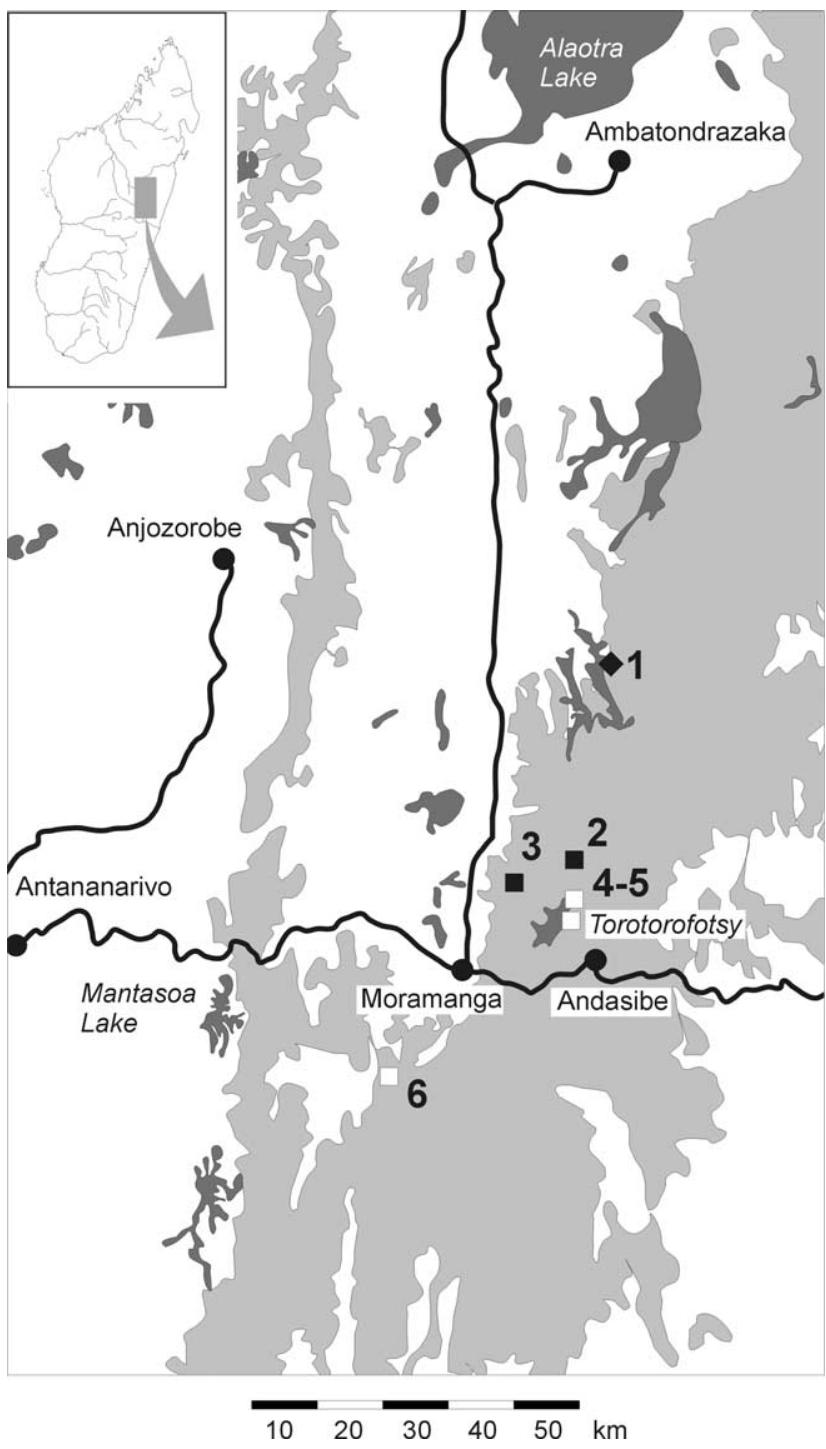

Fig. 1. Map of central eastern Madagascar with sampled populations of the M. madagascariensis group. Dark grey, lake or swamp areas; light grey, rainforest cover according to maps of the National Geographic Institute (FTM) of Madagascar (the present rainforest area is much further reduced according to recent satellite pictures), major roads in black. Localities are numbered as follows. M. milotympanum: 1, Fierenana; $M$. crocea: 2 , Ihofa; 3, Ambohimanarivo; $M$. aurantiaca: 4-5, Torotorofotsy, 6 Andranomena. See Table 2 for sample sizes at each locality.

nate from a single population. All confirmed sampling localities are shown in Fig. 1.

\subsection{DNA sequencing}

Genomic DNA was extracted from muscle tissue and toeclips using the Qiagen DNEasy tissue extraction kit following the manufacturer's instructions. Fragments of three mitochondrial genes (12S and $16 \mathrm{~S}$ rRNA, cytochrome $b$ ) and one nuclear gene (rhodopsin exon 1) were amplified via the polymerase chain reaction (PCR) in one specimen of each of the 15 species available. For the population genetic part of our study, we developed variants of universal primers that succeeded amplifying a large part of the moderately variable cytochrome $b$ gene in Mantella. Attempts of amplifying and sequencing the presumably more variable control region in Mantella were unsuccessful, probably because ranoid frogs can be characterised by important length polymorphisms of this gene (Sumida et al., 2000) and by a genomic rearrangement that led to the absence of conservative priming sites between the cytochrome $b$ and control region genes (Macey et al., 1997; Sumida et al., 2000, 2001).

One fragment of the $12 \mathrm{~S}$ rRNA gene and two fragments of the 16S rRNA gene (together ca. $1600 \mathrm{bp}$ ) were amplified using primers 12SA-L and 12SB-H, 16SA-L and $16 \mathrm{SB}-\mathrm{H}$, and 16SAH (reverse of 16SAL) and 16SL3, as previously published by Vences et al. (2000), Mausfeld et al. (2000), and Schaefer et al. (2002). A fragment of $925 \mathrm{bp}$ of the cytochrome $b$ gene was amplified using modified versions of the primers MVZ15-L and cytbAR-H from Goebel et al. (1999) (AAC TWA TGG CCC MCA CMA TMC GWA A and TAW ARG GRT CYT CKA CTG GTT G). Approximately $350 \mathrm{bp}$ of rhodopsin exon 1 was sequenced using primers Rhod1A and Rhod1D (Bossuyt and Milinkovitch, 2000).

PCRs were performed using the following conditions: an initial denaturation at $95^{\circ} \mathrm{C}$ for $1: 30 \mathrm{~min} ; 27-35 \mathrm{cy}-$ cles at $95^{\circ} \mathrm{C}$ for $0: 35 \mathrm{~min}$, primer-specific annealing temperatures for $0: 35 \mathrm{~min}$, extension at $72^{\circ} \mathrm{C}$ for 1:30 min; and final extension of 5:00 min at $72^{\circ} \mathrm{C}$. The primer specific annealing temperatures were $58^{\circ} \mathrm{C}(12 \mathrm{~S}$ rRNA), $55^{\circ} \mathrm{C}$ (rhodopsin and $16 \mathrm{~S}$ rRNA), and $45^{\circ} \mathrm{C}$ (cytochrome $b$ ). In cases where amplification was problematic, a touchdown approach from 55 to $45^{\circ} \mathrm{C}$ for 10 cycles was followed by 25 cycles at $45^{\circ} \mathrm{C}$.

PCR products were loaded onto $1.2 \%$ agarose gels, stained with ethidium bromide, and visualised on a "Gel Doc" system (Bio-Rad). If results were satisfying, products were purified using QIAquick spin columns (Qiagen) prior to cycle sequencing. A $10 \mu \mathrm{l}$ sequencing reaction included 1-2 $\mu 1$ template, $2.5 \mu 1$ sequencing buffer, $1 \mu \mathrm{l}$ of $2 \mathrm{pmol} / \mu \mathrm{l}$ primer, $2 \mu \mathrm{ABI}$ sequence mix, and 2.5-3.5 $\mu 1$ water. The sequence reaction was $27-35$ cycles of $0: 10 \mathrm{~min}$ at $92^{\circ} \mathrm{C}, 0: 10 \mathrm{~min}$ at $45^{\circ} \mathrm{C}$, and 4:00 min at $60^{\circ} \mathrm{C}$. Sequence data collection, visualisation, and analysis were performed on an ABI 3100 automated sequencer.

We obtained cytochrome $b$ sequences of 5-10 specimens from each population of the M. madagascariensis group sampled. Considering the relatively high differentiation and apparent haplotype sharing among species as observed in this data set, we performed a number of additional analyses to exclude the possibility of having sequenced nuclear pseudogene copies of the original 
mitochondrial gene (Bensasson et al., 2001): (a) the nucleotide sequences were translated into amino acids to exclude the possibility of frameshifts or stopcodons; (b) we ascertained that third positions displayed a deficit in guanine as typical for mitochondrial coding DNA fragments (guanine made up only $2.42 \%$ of third positions); (c) for all individuals of M. madagascariensis, we sequenced a shorter fragment (ca. $600 \mathrm{bp}$ ) using the primers Cytb-c and CBJ10933 from Bossuyt and Milinkovitch (2000), so as to verify that the overlapping parts were congruent with the sequences obtained using the MVZ-15L and CytbARH primers; and (d) for four $M$. aurantiaca specimens which had $M$. crocea-like haplotypes, we additionally sequenced $16 \mathrm{~S}$ rDNA and verified that also the $16 \mathrm{~S}$ rDNA haplotypes of these specimens clustered with $M$. crocea rather than with other M. aurantiaca. Sequences were deposited in GenBank (Accession Nos. AY263270-AY263322).

\subsection{Phylogenetic analyses}

Sequences were checked in BioEdit (North Carolina State University) or Sequence Navigator (Applied Biosystems) software and imported for alignment into Clustal X. Saturation plots were drawn using STATISTICA 6.0 (Statsoft, Inc. 2002) by plotting percent uncorrected sequence divergence against the number of transitions and transversions (rDNA) or substitutions at first, second, and third codon positions (cytochrome $b$, rhodopsin). Sequence alignment was straightforward. The cytochrome $b$ and rhodopsin sequences contained no indels and only few gaps were necessary to align to $12 \mathrm{~S}$ and $16 \mathrm{~S}$ rRNA sequences: 11 unambiguous gaps (single and isolated from others), one double gap in the outgroup, and one position in which a variable number of 1-3 gaps was needed. Because this low amount of indels was unlikely to provide much additional phylogenetic information, and because of the lack of general consensus of how to deal with gaps in phylogenetic analysis, we considered gapped positions as unreliable characters and excluded them from further analysis (Swofford et al., 1996).

Partition homogeneity was tested using the ILD test implemented in PAUP*, beta version 4b08 (Swofford, 2001), using heuristic searches with 1000 replicates. Because this test indicated inhomogeneity of the data partitions, we performed (1) separate analyses of each of the four genes as well as (2) a combined analysis of the complete data set concatenating all four genes (Yoder et al., 2001).

Maximum Parsimony (MP) and Maximum Likelihood (ML) analyses were carried out using PAUP*, using the heuristic search option with tree-bisectionreconnection (TBR) branch swapping and 100 random addition sequence replicates, following substitution model parameter estimatation with Modeltest version
3.06 (Posada and Crandall, 1998). SH-tests (Shimodaira and Hasegawa, 1999) as implemented in PAUP* were used to test alternative phylogenetic hypotheses.

Two thousand bootstrap replicates were calculated under the MP optimality criterion, while only $500 \mathrm{ML}$ bootstrap replicates were performed due to computational constraints. All bootstrapping was carried out using heuristic searches with 10 random addition sequence replicates and TBR branch swapping. Bayesian posterior probabilities were calculated using MrBayes, version 2.01 (Huelsenbeck and Ronquist, 2001) under a GTR substitution model with parameters estimated from the data. As much as 300,000 generations were run, every 10th tree was collected, and the number of initial generations needed before convergence on stable likelihood values was empirically estimated at 30,000; the burnin parameter was consequently set at $10 \%$.

\subsection{Phylogeography and population genetics}

This part of our study was based on cytochrome $b$ sequences from 49 individuals of the M. madagascariensis group. Some of these sequences had missing data at the beginning and end. These regions were excluded and the analyses were based on a $830 \mathrm{bp}$ segment that was available from all specimens and that contained no indels.

A minimum spanning network was constructed using the TCS software package (Clement et al., 2000), which employs the method of Templeton et al. (1992). It calculates the number of mutational steps by which pairwise haplotypes differ and computes the probability of parsimony (Templeton et al., 1992) for pairwise differences until the probability exceeds 0.95 . The number of mutational differences associated with the probability just before the 0.95 cut-off is then the maximum number of mutational connections between pairs of sequences justified by the 'parsimony' criterion, and these justified connections are applied in a haplotype network (Clement et al., 2000).

Hierarchical structuring of genetic variation was determined using analysis of molecular variance (AMOVA; Excoffier et al., 1992) as implemented in the Arlequin 2.0 software (Schneider et al., 2000). This analysis produces an output similar to conventional $F$ statistics, which describes the variation of haplotypes within single populations ( $\left.\Phi_{\mathrm{ST}}\right)$, among populations of a given group of populations, $\left(\Phi_{\mathrm{SC}}\right)$, and among species $\left(\Phi_{\mathrm{CT}}\right)$ both hierarchically and relative to all haplotypes (Barber, 1999). It should be noted that we define Mantella species here sensu Vences et al. (1999). Levels of significance were determined through 20,000 random permutations.

Population differentiation was analysed by testing the hypothesis of random distribution of individuals between pairs of populations (Raymond and Rousset, 
1995) using Arlequin 2.0 and computing 300,000 steps in the Markov chain.

\section{Results}

\subsection{Phylogenetic analyses}

Saturation plots were constructed in order to determine whether or not positions needed to be excluded prior to phylogenetic analyses. Fig. 2 shows that neither $16 \mathrm{~S}$ rRNA nor $12 \mathrm{~S}$ rRNA genes were saturated for transitions or transversions. Likewise, there was no evidence for saturation at third codon positions for cytochrome $b \quad\left(R^{2}=0.99\right)$ or rhodopsin $\left(R^{2}=0.74 ;\right.$ no tapering of slope at largest divergences). Therefore, all data were used in subsequent phylogenetic analyses. In addition, cytochrome $b$ and 16S rRNA showed gaps between clusters of points between approximately 8.0 and $13.0 \%$, and 0.75 and $2.0 \%$ sequence divergence, respectively, that largely corresponded to the divergences between and within species groups.

The partition homogeneity test rejected the null hypothesis of congruence of the included gene fragments at low significance $(P=0.04)$, indicating the need for their separate analyses. However, based on recent evidence provided by Yoder et al. (2001) and common practice with the same gene fragments in anurans (e.g., Bossuyt and Milinkovitch, 2000), we also performed a combined analysis of the concatenated sequences (Table 1).

After the exclusion of gapped sites, the complete data set of $12 \mathrm{~S}$ and $16 \mathrm{~S}$ rDNAs, cytochrome $b$, and rhodopsin consisted of 2840 characters, of which 2117 were invariant; 896 characters were variable, and of these, 484 were parsimony-informative.

Hierarchical likelihood tests implemented in Modeltest (Posada and Crandall, 1998) selected a Tamura-Nei substitution model $(\mathrm{TRN}+\mathrm{I}+\mathrm{G})$ as best fitting the combined data $(-\ln L=11369.4961)$, with base frequencies $\quad($ freq $\mathrm{A}=0.2934 ; \quad$ freqC $=0.2293 ; \quad$ freq $\mathrm{G}=$ 0.1628 ; freq $\mathrm{T}=0.3144)$ and substitution rates $\left(R_{[\mathrm{A}-\mathrm{G}]}=\right.$ 7.0129; $R_{[\mathrm{C}-\mathrm{T}]}=8.7806$; other rates $=1$ ) estimated from the data, a proportion of invariable sites of 0.4171 , and a gamma distribution shape parameter of 0.5396 .

The single obtained ML phylogram from the combined analysis (likelihood score 10481.49) is shown in Fig. 3. Maximum Parsimony searches recovered a single most parsimonious tree (1476 steps; consistency
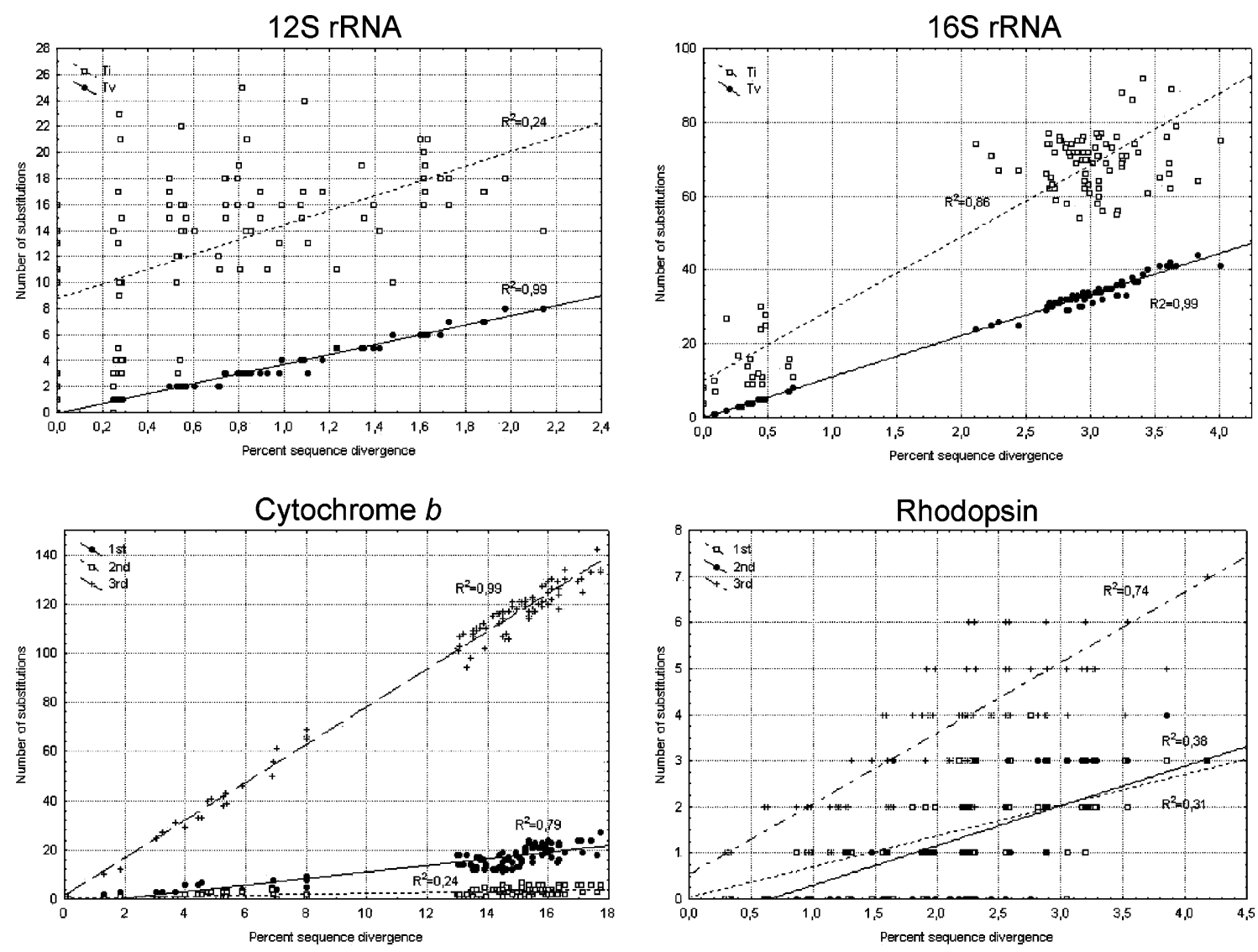

Fig. 2. Saturation plots for fragments of 16S rRNA, 12S rRNA, cytochrome $b$, and rhodopsin genes among species of Mantella (outgroup not included). For $16 \mathrm{~S}$ rRNA and $12 \mathrm{~S}$ rRNA, percent uncorrected sequence divergence was plotted against the number of transitions (Ti) and transversions (Tv). Percent uncorrected sequence divergence was plotted against the number of substitutions at first, second, and third codon positions for cytochrome $b$ and rhodopsin genes. 
Table 1

Summary of combined and separate phylogenetic analyses of gene fragments

\begin{tabular}{|c|c|c|c|c|c|c|c|c|c|c|}
\hline Node & Description & $\begin{array}{l}\text { ML } \\
\text { (all) }\end{array}$ & $\begin{array}{l}\text { MP } \\
\text { (all) }\end{array}$ & $\begin{array}{l}\text { Bayesian } \\
\text { (all) }\end{array}$ & $\begin{array}{l}\text { ML } \\
\text { (rRNA) }\end{array}$ & $\begin{array}{l}\text { MP } \\
\text { (rRNA) }\end{array}$ & $\begin{array}{l}\text { ML (Cyt } \\
\text { b) }\end{array}$ & $\begin{array}{l}\text { MP (Cyt } \\
\text { b) }\end{array}$ & $\begin{array}{l}\text { ML } \\
\text { (Rhod) }\end{array}$ & $\begin{array}{l}\text { MP } \\
\text { (Rhod) }\end{array}$ \\
\hline 1 & M. bernhardi most basal & $+(67)$ & + & $+(99)$ & $+(88)$ & + & - & - & - & - \\
\hline $1 a$ & M. laevigata most basal & - & - & - & - & - & + & $+(72)$ & + & + \\
\hline $1 b$ & $\begin{array}{l}\text { M. bernhardi in a clade } \\
\text { with } M . \text { cowani group }\end{array}$ & - & - & - & - & - & $+(66)$ & - & $+(56)$ & $+(54)$ \\
\hline 2 & $\begin{array}{l}\text { M. madagascariensis } \\
\text { group in a clade with } \\
\text { M. laevigata/M. betsileo } \\
\text { groups }\end{array}$ & $+(67)$ & $+(59)$ & $+(100)$ & $+(85)$ & $+(72)$ & - & - & - & $(-)$ \\
\hline 3 & $\begin{array}{l}\text { M. laevigata sister to } \\
\text { M. betsileo group }\end{array}$ & $+(88)$ & + & $+(100)$ & $+(97)$ & $+(92)$ & - & - & - & $(-)$ \\
\hline $3 a$ & $\begin{array}{l}\text { M. madagascariensis } \\
\text { group sister to } M \text {. betsileo } \\
\text { group }\end{array}$ & - & - & - & - & - & + & $+(68)$ & - & - \\
\hline 4 & M. cowani group & $+(100)$ & $+(100)$ & $+(100)$ & $+(99)$ & $+(100)$ & $+(98)$ & $+(100)$ & + & $(-)$ \\
\hline 5 & $\begin{array}{l}\text { M. madagascariensis } \\
\text { group }\end{array}$ & $+(98)$ & $+(100)$ & $+(100)$ & $+(97)$ & $+(100)$ & $+(70)$ & $+(100)$ & - & $(-)$ \\
\hline 6 & M. betsileo group & $+(100)$ & $+(100)$ & $+(100)$ & $+(97)$ & $+(100)$ & $+(96)$ & $+(100)$ & - & - \\
\hline 7 & $\begin{array}{l}\text { M. aff. betsileo sister to } \\
\text { M. expectata }\end{array}$ & $+(84)$ & + & $+(100)$ & $+(53)$ & - & - & $(-)$ & - & - \\
\hline $7 a$ & $\begin{array}{l}\text { M. expectata most basal } \\
\text { in } M \text {. betsileo group }\end{array}$ & - & - & - & - & $+(69)$ & - & $(-)$ & $(-)$ & - \\
\hline 8 & $\begin{array}{l}\text { M. betsileo sister to } \\
\text { M. viridis }\end{array}$ & $+(99)$ & $+(100)$ & $+(100)$ & $+(81)$ & $+(98)$ & $+(99)$ & + (99) & - & - \\
\hline 9 & $\begin{array}{l}\text { M. crocea sister to } \\
\text { M. milotympanum }\end{array}$ & $+(100)$ & $+(100)$ & $+(100)$ & $+(99)$ & $+(100)$ & $+(98)$ & $+(100)$ & - & + \\
\hline 10 & $\begin{array}{l}\text { M. pulchra sister to } \\
\text { M. madagascariensis }\end{array}$ & $+(99)$ & $+(98)$ & $+(100)$ & - & - & $+(93)$ & $+(100)$ & $(-)$ & $(-)$ \\
\hline $10 a$ & $\begin{array}{l}\text { M. aurantiaca sister to } \\
\text { M. madagascariensis }\end{array}$ & - & - & - & $+(72)$ & $+(64)$ & - & - & $(-)$ & $(-)$ \\
\hline 11 & $\begin{array}{l}\text { M. aurantiaca most basal } \\
\text { in } M . \text { madagascariensis } \\
\text { group }\end{array}$ & $+(64)$ & $+(69)$ & $+(83)$ & - & - & $+(73)$ & $+(78)$ & - & $(-)$ \\
\hline $11 a$ & $\begin{array}{l}\text { M. pulchra most basal in } \\
\text { M. madagascariensis } \\
\text { group }\end{array}$ & - & - & - & $+(56)$ & $+(72)$ & - & - & - & $(-)$ \\
\hline 12 & $\begin{array}{l}\text { M. nigricans sister to } \\
\text { M. baroni }\end{array}$ & $+(99)$ & $+(100)$ & $+(100)$ & $+(92)$ & $+(94)$ & $+(86)$ & $+(100)$ & - & $(-)$ \\
\hline 13 & $\begin{array}{l}\text { M. cowani most basal in } \\
\text { M. cowani group }\end{array}$ & $+(88)$ & $+(97)$ & + (99) & $(-)$ & $+(76)$ & $+(78)$ & $+(96)$ & - & $(-)$ \\
\hline
\end{tabular}

+ , a certain topology was supported in the analysis; -, the topology was not supported; and (-), the topology was not resolved but was compatible with the node. Numbers in parentheses are bootstrap support values (ML, MP) and Bayesian posterior probabilities (only given if $>50 \%$ ). Numbering of nodes corresponds to Fig. 3; numbers followed by $a$ or $b$ are alternative topologies not favored by the combined analysis.

index $=0.622$, retention index $=0.694$ ) that completely agreed with this topology. These trees as well as the Bayesian analysis supported monophyly of named species groups (Schaefer et al., 2002: M. betsileo group, $M$. cowani group, and M. madagascariensis group). Bootstrap values for these groups were $>95 \%$ and posterior probabilities were $100 \%$. ML searches constraining the topology to monophyletic groups containing either the two uniformly colored orange Mantella species ( $M$. aurantiaca and $M$. milotympanum) or the two species with distinct dorsal black-yellow-orange color contrast (M. madagascariensis and $M$. baroni) recovered trees with significantly lower likelihood values. These were 10988.47 (M. madagascariensis placed sister to M. baroni; remaining topology as in Fig. 3) and 10543.54 (M. aurantiaca placed sister to $M$. milotympanum). Both topologies were significantly worse than the preferred topology (Fig. 3) as assessed by SH tests $(P<0.001$ and $P<0.05$, respectively).

Although almost all nodes were well supported in the combined analysis (Fig. 3), the separate analyses as summarised in Table 1 revealed conflicts between the major data sets. Modeltest suggested different substitution models for the three data partitions: a general timereversible $(G T R+G)$ model with a gamma distribution shape parameter of 0.1469 for the rRNA genes, a Tamura-Nei $(\operatorname{TrN}+\mathrm{I}+\mathrm{G})$ model with a proportion of invariable sites of 0.5683 and a gamma distribution shape parameter of 1.7085 for the cytochrome $b$ gene, and a Kimura model $(\mathrm{K} 80+\mathrm{G})$ with a gamma distri- 


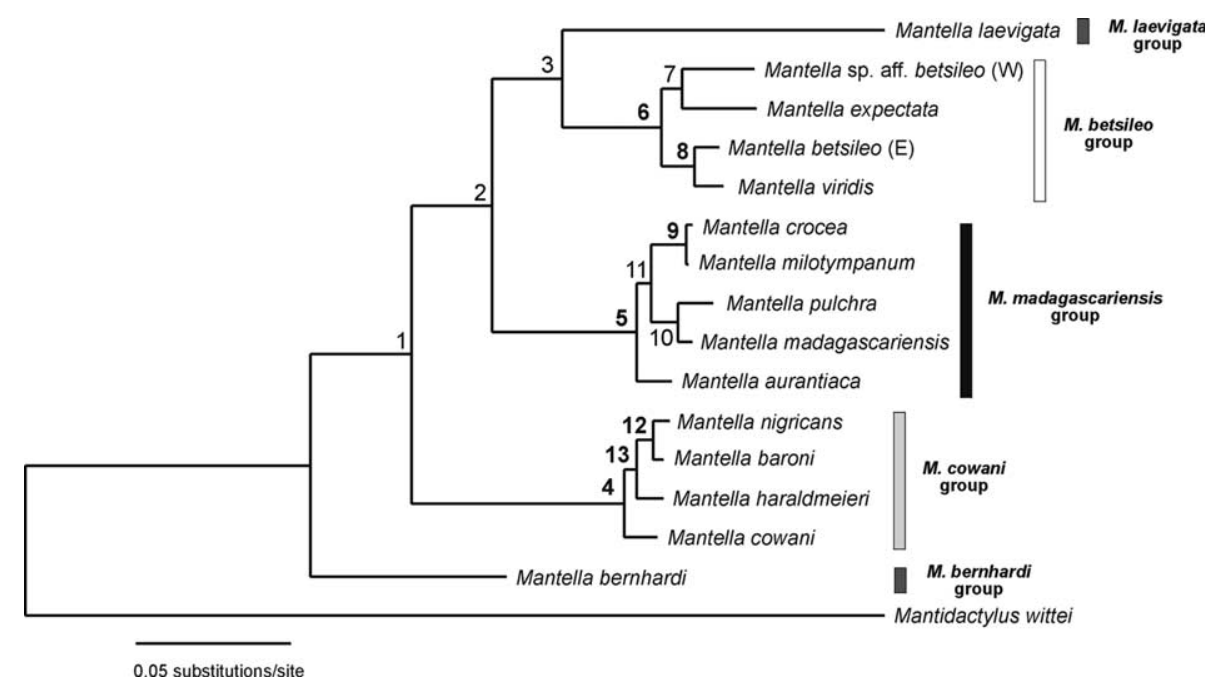

Fig. 3. Maximum Likelihood phylogram of 15 species of Mantella, based on 2840 bp of the rhodopsin, cytochrome $b, 12 \mathrm{~S}$ rRNA, and 16S rRNA genes. The tree was obtained by heuristic searches in PAUP* based on a GTR + I + G substitution model suggested by Modeltest (Posada and Crandall, 1998). For bootstrap values and Bayesian posterior probabilities of the numbered nodes, see Table 1 . All nodes except for No. 11 received ML bootstrap values $\geqslant 75 \%$ and posterior probabilities $\geqslant 99 \%$. Nodes numbered in boldface were congruently supported by separate analyses of rRNA genes and cytochrome $b$.

bution shape parameter of 0.0141 for rhodopsin. Separate ML searches recovered single trees with likelihoods of 5078.72 (rDNA), 4450.06 (cytochrome $b$ ), and 755.66 (rhodopsin). These largely agreed with the obtained MP trees (Table 1): rDNA, a single most parsimonious tree of 635 steps (216 parsimony-informative characters); cytochrome $b$, three trees of 778 steps (252 parsimonyinformative characters); and rhodopsin, 55 trees of 41 steps (16 parsimony-informative characters).

The rhodopsin tree did not resolve most phylogenetic relationships, almost certainly because of the low number of phylogenetically informative characters. The cytochrome $b$ and rDNA trees differed in two major aspects (Table 1): (1) the rDNA analysis placed $M$. bernhardi as most basal species, whereas the cytochrome $b$ analysis placed $M$. laevigata at the most basal position; (2) the rDNA analysis placed M. madagascariensis as sister species of $M$. aurantiaca, whereas the cytochrome $b$ data favored a sister-group relationship between $M$. madagascariensis and M. pulchra.

\subsection{Phylogeography and population genetics}

Three haplotype networks were recovered by TCS based on cytochrome $b$ sequences of 49 individuals from seven populations (Fig. 4). These networks largely corresponded to individuals of (1) M. madagascariensis, (2) M. aurantiaca, and (3) M. crocea and M. milotympanum. They were not connected with each other due to the large genetic distance ( $\gg 12$ steps at $95 \%$ probability threshold) between their haplotypes. The number of pairwise substitutions was 44-51 between $M$. madagascariensis and $M$. aurantiaca, 39-46 between M. madagascariensis and M. milotympanum/crocea, and 38-47 between haplotypes of the M. aurantiaca and M. milotympanum/crocea networks. These differences translated into a maximum of three amino acid substitutions among taxa, 0-3 amino acid substitutions within $M$. madagascariensis, and $0-1$ within $M$. aurantiaca. No amino acid substitution was detected within the M. milotympanum/M. crocea clade.

The first haplotype network contained the seven $M$. madagascariensis individuals. Among these, four haplotypes were identified, with a maximum divergence of six steps.

The second network contained six haplotypes from 17 out of $21 \mathrm{M}$. aurantiaca individuals. It consisted of two major groups that differed by a minimum of seven substitutions. One of these groups corresponded to the individuals from Andranomena, the other to the specimens from the first site sampled in the Torotorofotsy swamp. The second site in this swamp harboured haplotypes belonging to both groups. Four other $M$. aurantiaca (from Andranomena) belonged to the $M$. milotympanum-M. crocea haplotype network and one of these (from a single individual) was identical to the most common haplotype found in $M$. crocea from Ihofa.

This third haplotype network connected M. milotympanum with the two populations of $M$. crocea. The Ihofa and Ambohimanarivo populations of M. crocea differed by a maximum of seven steps and a minimum of one step, although no haplotype sharing was observed. A single $M$. milotympanum had a sequence identical to the second $M$. crocea haplotype from Ihofa, while the other M. milotympanum haplotypes were unique to this species and differed by $1-5$ steps from the nearest M. crocea haplotype. 


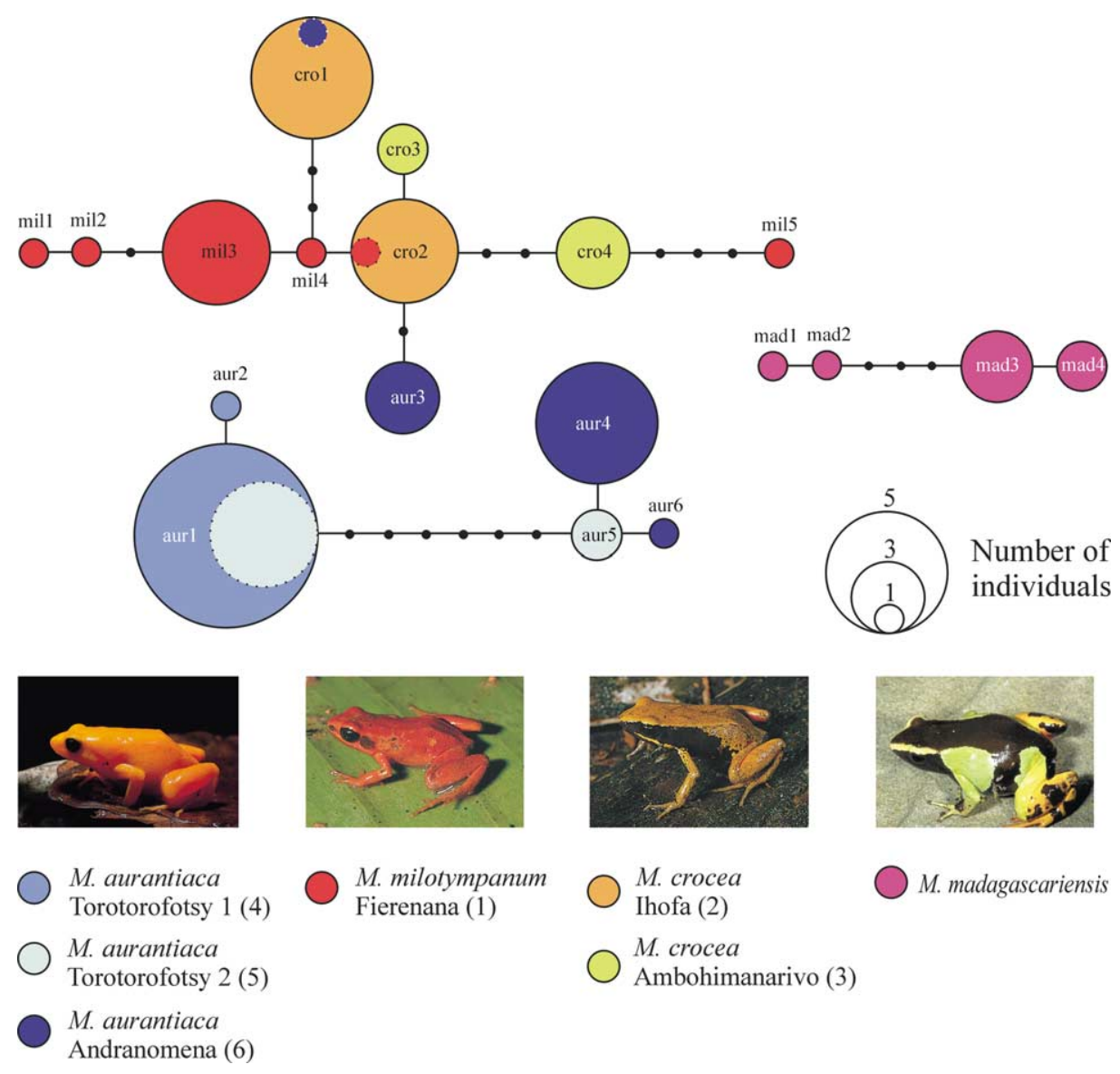

Fig. 4. Haplotype networks of species and populations of the M. madagascariensis group (49 individuals), based on 830 bp of the cytochrome $b$ gene. Networks were not joined if haplotypes were separated by more than 12 mutations. Each circle represents one haplotype; size of circles is proportional to haplotype frequency. Circles within larger circles (with dotted outline) represent haplotype sharing between two populations. Small black dots represent putative haplotypes that were not observed. Haplotypes are named aur1-aur6, cro1-cro4, mil1-mil4, and mad1-mad4 according to the species in which they were found (or in which they occur most frequently. Populations are numbered (in parentheses) according to Fig. 1.

Haplotype diversity in the studied populations of the M. madagascariensis group is summarised in Table 2 . Within populations we found 2-6 haplotypes, with a nucleotide diversity of $0.10-0.45 \%$ in all populations except Andranomena. In this M. aurantiaca population, nucleotide diversity was $2.86 \%$ due to haplotype sharing

Table 2

Summary of haplotype diversity in the M. madagascariensis group populations examined

\begin{tabular}{|c|c|c|c|c|c|}
\hline Species and population & Sample size & Haplotypes & Polymorphic sites & Gene diversity & Nucleotide diversity $(100 \times)$ \\
\hline \multicolumn{6}{|l|}{ M. milotympanum } \\
\hline Fierenana (1) & 9 & 6 & 12 & $0.83 \pm 0.13$ & $0.42 \pm 0.27$ \\
\hline \multicolumn{6}{|l|}{ M. crocea } \\
\hline Ihofa (2) & 5 & 2 & 4 & $0.60 \pm 0.18$ & $0.29 \pm 0.22$ \\
\hline Ambohimanarivo (3) & 7 & 2 & 4 & $0.57 \pm 0.12$ & $0.28 \pm 0.20$ \\
\hline \multicolumn{6}{|l|}{ M. aurantiaca } \\
\hline Torotorofotsy 1 (4) & 6 & 2 & 7 & $0.53 \pm 0.17$ & $0.45 \pm 0.31$ \\
\hline Torotorofotsy 2 (5) & 5 & 2 & 2 & $0.40 \pm 0.24$ & $0.10 \pm 0.10$ \\
\hline Andranomena (6) & 10 & 4 & 48 & $0.71 \pm 0.12$ & $2.86 \pm 1.56$ \\
\hline \multicolumn{6}{|l|}{ M. madagascariensis } \\
\hline Marolambo & 7 & 4 & 6 & $0.81 \pm 0.13$ & $0.32 \pm 0.22$ \\
\hline
\end{tabular}

Populations are labelled (numbers in parentheses) according to Fig. 1. Data refer to a fragment of $830 \mathrm{bp}$ of the cytochrome $b$ gene. Indices and sampling variances in the last two columns were computed using Arlequin 2.0 software; they represent the probability that two randomly chosen haplotypes are different in the sample (gene diversity) and that two randomly chosen homologous nucleotides are different in the sample (nucleotide diversity; given in percent). 
Table 3

Summary of $\Phi$-statistics produced by AMOVA, with populations grouped according to their species assignment

\begin{tabular}{llll}
\hline & $F$ & $\%$ & $P$ \\
\hline Among species $\left(\Phi_{\mathrm{CT}}\right)$ & 0.66039 & 66.04 & 0.05 \\
Among populations $\left(\Phi_{\mathrm{SC}}\right)$ & 0.39372 & 13.37 & 0.01 \\
Within populations $\left(\Phi_{\mathrm{ST}}\right)$ & 0.79410 & 20.59 & 0.001 \\
\hline
\end{tabular}

$P$ values were determined by a random permutation test with 20,000 replicates, and indicate the significance of random value $>$ observed value for $\Phi_{\mathrm{CT}}$ and $\Phi_{\mathrm{SC}}$, and of random value $<$ observed value for $\Phi_{\mathrm{ST}}$.

with $M$. crocea. The exact test of population differentiation revealed a significant genetic structuring in the overall data set $(P<0.001)$ and in all pairwise comparisons $(P<0.005)$ except for that between the two $M$. aurantiaca populations from Torotorofotsy, which are also closest to each other geographically. AMOVA revealed a greater than randomly expected differentiation within populations and a smaller than expected variation among populations and species (Table 3).

\section{Discussion}

\subsection{Phylogenetic relationships in Mantella}

Our phylogeny confirms that five major clades can be distinguished within Mantella, corresponding to $M$. bernhardi, M. laevigata, and the $M$. betsileo, M. cowani and $M$. madagascariensis species groups. This is in general agreement with hypotheses based on osteological characters (Vences et al., 1998b) and allozymes (Vences et al., 1998c). However, most basal splits between species groups remain unresolved, despite combining more than $2.8 \mathrm{kbp}$ of mitochondrial noncoding, coding, and nuclear sequences.

Within the M. madagascariensis group, the large data set analysed here, and especially the inclusion of cytochrome $b$ sequences, contributed to resolving one apparent conflict between allozyme and DNA sequence data. In the 16S rDNA analysis of Schaefer et al. (2002), $M$. aurantiaca appeared as the sister group of $M$. madagascariensis, whereas $M$. pulchra was considered the most basal species in the group. Allozyme data suggested that M. madagascariensis and M. pulchra were sister species, in agreement with their color pattern (yellowish flank blotches), karyology (Odierna et al., 2001), and distribution in rainforest. In contrast, the other three species of the group lack flank blotches and our fieldwork confirmed that they mainly live in gallery forests of swamp areas. The combined analysis (Fig. 3) as well as the cytochrome $b$ data (Table 1) also support this hypothesis from a mitochondrial perspective, and indicate that the alternative topology suggested by rRNA genes might be due to the low number of infor- mative sites among these genetically similar species. However, none of the mitochondrial data sets placed $M$. aurantiaca as sister group to the $M$. crocealM. milotympanum clade, which suggests non-monophyly of these three swamp-dwelling forms but is not in agreement with allozyme results. Allozymes are largely coded by nuclear genes, and the results may indicate a conflict between nuclear and mitochondrial DNA relationships. To test this hypothesis, analysis of more variable nuclear molecular markers (e.g., microsatellites or SNPs) would be most informative.

\subsection{Differentiation within the M. madagascariensis group}

The high number of steps (at least 38) separating the haplotypes from the networks in Fig. 4 shows that there is relevant genetic differentiation between $M$. aurantiaca and $M$. madagascariensis, and of either species relative to $M$. crocea or $M$. milotympanum. This corroborates the species status of $M$. aurantiaca, M. madagascariensis, and $M$. crocea, but sheds doubts on the validity of the species status of $M$. milotympanum. This name was coined for a color variant in the pet trade, which was subsequently tentatively accepted as a species (Vences et al., 1999). Although this form may actually be a synonym of $M$. crocea, we consider additional studies in the contact zones between the two species necessary before making firm conclusions on the matter.

One of the most surprising findings was the deep haplotype sharing between $M$. crocea and $M$. aurantiaca in the Andranomena population of $M$. aurantiaca. It was observed in four specimens and confirmed by $16 \mathrm{~S}$ rDNA sequences of these that also clustered with $M$. crocea rather than with other $M$. aurantiaca (data not shown). The haplotypes of about 10 other mantellid species of which 5-10 cytochrome $b$ sequences from one or few populations were available (data not shown) never revealed instances of such high intraspecific divergence. The Andranomena population is geographically most distant from the distribution area of $M$. crocea (Fig. 1), and no haplotype sharing was found between populations of $M$. crocea and $M$. aurantiaca that live in relatively close proximity.

The general pattern shown by the haplotype network indicates only limited congruence between geography and genetic distance. For instance, one M. milotympanum individual showed a haplotype that was closer to the Ambohimanarivo $M$. crocea population than to other M. milotympanum. In $M$. aurantiaca, the second Torotorofotsy population shared haplotypes with Andranomena while being geographically most distant from it.

Quaternary records show that at least central Madagascar has experienced periods of fluctuating climate with varying vegetation cover (Burney, 1996). The impact of ice ages on Madagascar is also evident from the 
recent discovery of signs of past glacial activity in the Andringitra Massif (Vidal-Romaní et al., 1997). Because $M$. aurantiaca, $M$. crocea, and $M$. milotympanum predominantly live in swamp gallery forests at the edge of the main eastern rainforest block, it would be sound to hypothesise that these frogs have repeatedly been isolated in small refugia there and then evolved distinct color patterns and haplotypes, and subsequently expanded their population sizes again, with intensive introgression of haplotypes in the contact zones. This scenario is not improbable because successful hybridisation of species of the M. madagascariensis group has been regularly observed in captivity (Glaw et al., 2000). An alternative scenario would assume an old origin of the haplotype divergences, and a more recent differentiation of the population into different color morphs and species with incomplete lineage sorting.

The haplotype diversity found within populations of the $M$. madagascariensis group is relatively high when compared to other amphibians. Riberon et al. (2002) observed an extreme instance of lack of genetic diversity in Salamandra lanzai, with 44 specimens from 12 populations being totally invariant over $1050 \mathrm{bp}$ of cytochrome $b$. Similarly, in 50 individuals from 13 populations of the highland Salamandra atra, no genetic variation was found within populations, while interpopulation genetic distance was $0-3.1 \%$ (Riberon et al., 2001). García-Paris and Jockusch (1999) found only four haplotypes in seven populations of painted frogs (Discoglossus galganoi) over a wide geographic area, with haplotype divergences of $0.3-1.6 \%$. Tan and Wake (1995) sequenced two individuals for most studied populations of Taricha newts and assessed that most individuals from the same population had identical DNA sequences. Tarkhnishvili et al. (2000) sequenced a $350 \mathrm{bp}$ fragment in 73 Mertensiella salamanders and found two different haplotypes $(0.6 \%$ divergence) in only one out of 10 populations while all other populations had unique haplotypes. García-Paris et al. (2000) emphasise high levels of genetic differentiation among Neotropical salamanders (Bolitoglossa), referring to nine haplotypes in three populations of one species (16 individuals sequenced for $647 \mathrm{bp}$ ) which still is less variation than that encountered by us in species of the M. madagascariensis group.

However, some other examples of high cytochrome $b$ variability in amphibians also do exist. Analysing a fragment of only $329 \mathrm{bp}$ in 17 populations of the goldenstriped salamander Chioglossa lusitanica, Alexandrino et al. (2000) found 1-4 haplotypes per population (mean 1.76), with a sequence divergence between haplotypes of up to $3.2 \%$ and an overall nucleotide diversity of $1.4 \%$. A subsequent study in which $700 \mathrm{bp}$ was sequenced in 124 individuals from 17 localities identified 30 haplotypes with sequence divergence ranging from 0.14 to $2.14 \%$ and an overall nucleotide diversity of $0.99 \%$
(Alexandrino et al., 2002). They found that 10 out of 12 localities with samples of $n>5$ were polymorphic with 2-5 haplotypes differing by 1-5 mutations. Barber (1999) observed up to six different haplotypes within populations of the Canyon treefrog Hyla arenicolor (360 bp analysed), and AMOVA revealed that up to 30\% of the overall variation was explained by withinpopulation variance. These values compare well with those we found in our study of Mantella, with 2-6 haplotypes per population, an average nucleotide diversity of $0.67 \%$ and for which $>20 \%$ of intrapopulation variance accounted for the overall genetic variation $(p<0.001)$.

\subsection{Homoplasy of color patterns}

The phylogenetic hypothesis presented here, in conjunction with the phylogeographic structuring among populations within the $M$. madagascariensis group, suggests that coloration is an evolutionarily labile trait among Mantella. The hypothesis of homoplastic evolution of dorsal pigment pattern in $M$. baroni and $M$. madagascariensis based on 16S rDNA sequences (Schaefer et al., 2002) is corroborated further by the distant placement of these two taxa in the cytochrome $b$ analysis, and in a limited way also in the rhodopsin analysis herein. These two species show a pattern that is extremely similar in the arrangement of black, yellow, and orange aposematic elements and is very unlikely to represent a retainment of ancestral features. Our data provide with sufficient probability a second instance of such convergent color evolution in Mantella: M. milotympanum and $M$. aurantiaca are both uniformly orange-golden, with $M$. milotympanum having some black pigment around the tympanum and nostril. These two species are not sister to each other, and no haplotype sharing was observed between them. Geographically, they are most separated, with differently colored $M$. crocea populations intercalated between their distribution areas. Because the non-uniform color is ancestral also for M. aurantiaca based on ontogenetic observations (Glaw et al., 2000), it can be assumed that the uniform orange color of $M$. aurantiaca and M. milotympanum has arisen twice.

Mate recognition in most frogs is largely based on the advertisement calls of males, but in some diurnal species, optical communication has been demonstrated (Hödl and Amezquita, 2001). The conspicuous and contrasting white or black color of vocal sacs in males of several species of mantellids, among them Mantella betsileo, Mantidactylus liber, and Mantidactylus granulatus (Glaw and Vences, 1994), may be related to mate recognition as well. The same might be true for other, sexually non-dimorphic traits such as the conspicuous eye coloration of many otherwise cryptic arboreal species (Glaw and Vences, 1997). 
Species within the M. madagascariensis group show little bioacoustic differentiation (Andreone, 1992; Glaw and Vences, 1994). Assortative mating based on color pattern would be plausible in diurnal frogs such as Mantella. Selection on coloration could act as a reproductive barrier over small geographic scales, in combination with its function in predator-deterrence, and could provide at least a partial explanation for the fast evolution of the strikingly divergent patterns in the $M$. madagascariensis group. However, so far there has been no observation of such a mechanism in Mantella or in other anurans, and this hypothesis therefore remains entirely speculative.

\subsection{Conservation implications}

Prior to the sampling carried out for the present study, the only precisely known locality for any of the three species $M$. aurantiaca, M. crocea, and M. milotympanum was the Torotorofotsy area (for M. aurantiaca; including Ambatodradama which is probably in the same region), whereas all other distributional knowledge relied on unpublished reports or unconfirmed personal communications of commercial exporters (Vences et al., 1999; Zimmermann and Hetz, 1992). Our field observations therefore provide the first accurate locality data for $M$. crocea and M. milotympanum, and demonstrate that $M$. aurantiaca is not confined to Torotorofotsy but also occurs at least at one additional locality, Andranomena. The existence of further populations is to be expected, but there is no indication that the general distribution of these species will extend far north or south of the known area. Despite recent efforts to extend the borders of Mantadia National Park to include the Torotorofotsy area (Zimmermann, 1996), currently none of the known localities benefit from any legal protection. Two major threats are conceivable for these frogs: destruction of their habitats and overcollecting.

Unprotected forests are known to be under strong human pressure in Madagascar and may completely disappear in the near future with continued deforestation rates (Green and Sussman, 1990). One of the major causes for forest destruction is slash- and burn-agriculture which, for instance, has led to the near complete disappearance of the habitat at the type locality of $M$. bernhardi in south-eastern Madagascar (Raxworthy and Nussbaum, 2000). Our observations in the habitats of Mantella aurantica, M. crocea, and M. milotympanum conform to this observation. In December 2001, we witnessed the aftermath of an uncontrolled forest fire at Torotorofotsy that destroyed at least $30 \%$ of the swamp gallery forest populated by $M$. aurantiaca in this area. In addition, small-scale logging was observed at all sites visited.

By interviewing local collectors at Andranomena and Ambohimanarivo, we learned that large numbers of specimens of $M$. aurantiaca and $M$. crocea are being collected from these sites. Estimates ranged from 5000 to 20,000 individuals collected yearly from each population for the past 5-10 years. Nevertheless, all visited populations appeared to be healthy and many frogs were observed during our short visits (e.g., over $50 \mathrm{M}$. aurantiaca specimens in Andranomena in less than $1 \mathrm{~h}$ ).

From these observations, habitat destruction through logging and forest fires seems to be the most important threats for the populations of these three species, while collecting does not appear to have disastrous consequences for the populations involved. The genetic results herein contribute threefold to assessing the threats and outlining a conservation strategy for these frogs:

First, our data show that $M$. aurantiaca and $M$. crocea/milotympanum constitute two genetically well differentiated entities - most probably at the species level-and thus that each merits intensive conservation measures.

Second, the high genetic diversity found in all populations indicates a moderate to high effective population size in past generations. Considering that Mantella have short generation times and can reproduce within one year after metamorphosis (Glaw et al., 2000), our data provide no evidence for bottleneck events that could have resulted from overcollecting during the past 10 years.

Third, the relatively high degree of haplotype sharing in our limited sample indicates that gene flow between populations took place until recently. This agrees with past habitat continuity as visible from topographic maps. A future discovery of isolated populations with strongly divergent haplotypes seems unlikely, and the conservation of a few large populations will save a significant part of the species' genetic diversity.

\section{Acknowledgments}

This study was carried out in the framework of a cooperation accord between the University of Antananarivo, Madagascar, and the University of Amsterdam, Netherlands. We are grateful to Ildiko Somorjai who contributed many data and was of help in the field, to Euan Edwards for his invaluable logistic assistance, and to the Malagasy authorities for research and export permits. The work was supported by grants of the Deutsche Forschungsgemeinschaft DFG (VE247/1-1 and VE247/1-2).

\section{References}

Alexandrino, J., Froufe, E., Arntzen, J.W., Ferrand, N., 2000. Genetic subdivision, glacial refugia and postglacial recolonization in the 
golden-striped salamander, Chioglossa lusitanica (Amphibia: Urodela). Mol. Ecol. 9, 771-781.

Alexandrino, J., Arntzen, J.W., Ferrand, N., 2002. Nested clade analysis and the genetic evidence for population expansion in the phylogeography of the golden-striped salamander, Chioglossa lusitanica (Amphibia: Urodela). Heredity 88, 66-74.

Andreone, F., 1992. Syntopy of Mantella cowani Boulenger and Mantella madagascariensis (Grandidier) in central-eastern Madagascar, with notes on the coloration in the genus Mantella (Anura: Mantellidae). Boll. Mus. Reg. Sci. Nat. Torino 10, 421-450.

Barber, P.H., 1999. Patterns of gene flow and population genetic structure in the canyon treefrog, Hyla arenicolor (Cope). Mol. Ecol. $8,563-576$.

Behra, O., 1993. The export of reptiles and amphibians from Madagascar. TRAFFIC Bull. 13, 115-116.

Bensasson, D., Zhang, D.-X., Hartl, D.L., Hewitt, G.M., 2001. Mitochondrial pseudogenes: evolution's misplaced witnesses. Trends Ecol. Evol. 16, 314-321.

Bossuyt, F., Milinkovitch, M.C., 2000. Convergent adaptive radiations in Madagascan and Asian ranid frogs reveal covariation between larval and adult traits. Proc. Natl. Acad. Sci. USA 97, 6585-6590.

Burney, D.A., 1996. Climate and fire ecology as factors in the quaternary biogeography of Madagascar. In: Lourenço, W.R. (Ed.), Actes du Colloque International Biogéographie de Madagascar. Société de Biogéographie, Paris, pp. 49-58.

Caldwell, J.P., 1996. The evolution of myrmecophagy and its correlates in poison frogs (Family Dendrobatidae). J. Zool. (Lond.) 240, 75101.

Clement, X., Posada, D., Crandall, K., 2000. TCS: A computer program to estimate gene genealogies. Mol. Ecol. 9, 1657-1659.

Daly, J.W., Andriamaharavo, N.R., Andriantsiferana, M., Myers, C.W., 1996. Madagascan poison frogs (Mantella) and their skin alkaloids. Am. Mus. Novit. 3177, 1-34.

Daly, J.W., Garraffo, H.M., Hall, G.S.H., Cover Jr., J.F., 1997. Absence of skin alkaloids in captive-raised Madagascan mantelline frogs (Mantella) and sequestration of dietary alkaloids. Toxicon 35, 1131-1135.

Excoffier, L., Smouse, P.E., Quattro, J.M., 1992. Analysis of molecular variance inferred from metric distances among DNA haplotypes: application to human mitochondrial restriction data. Genetics 131, 479-491.

García-Paris, M., Jockusch, E.L., 1999. A mitochondrial DNA perspective on the evolution of Iberian Discoglossus (Amphibia: Anura). J. Zool. (Lond.) 248, 209-218.

García-Paris, M., Good, D.A., Parra-Olea, G., Wake, D.B., 2000. Biodiversity of Costa Rican salamanders: implications of high levels of genetic differentiation and phylogeographic structure for species formation. Proc. Natl. Acad. Sci. USA 97, 1640-1647.

Glaw, F., Vences, M., 1994. A Fieldguide to the Amphibians and Reptiles of Madagascar, second ed. Vences and Glaw, Köln.

Glaw, F., Vences, M., 1997. A review of anuran eye colouration: definitions, taxonomic implications and possible functions. In: Böhme, W., Bischoff, W., Ziegler, T. (Eds.), Herpetologia Bonnensis (Proceedings of the Eigth Ordinary General Meeting of the Societas Herpetologica Europaea). Bonn (SEH), pp. 125-138.

Glaw, F., Vences, M., 2000. Current counts of species diversity and endemism of Malagasy amphibians and reptiles. In: Lourenço, W.R., Goodman, S.M. (Eds.), Diversité et endémisme a Madagascar. Mémoires de la Société de Biogéographie, Paris, pp. 243-248.

Glaw, F., Schmidt, K., Vences, M., 2000. Nachzucht, Juvenilfärbung und Oophagie von Mantella laevigata im Vergleich zu anderen Arten der Gattung (Amphibia: Ranidae). Salamandra 36, 1-24.

Goebel, A.M., Donnelly, J.M., Atz, M.E., 1999. PCR primers and amplification methods for $12 \mathrm{~S}$ ribosomal DNA, the control region, cytochrome oxidase I, and cytochrome $b$ in bufonids and other frogs, and an overview of PCR primers which have amplified DNA in amphibians successfully. Mol. Phylogenet. Evol. 11, 163-199.
Green, G.M., Sussman, R.W., 1990. Deforestation history of the eastern rain forest of Madagascar from satellite images. Science $248,212-215$

Hödl, W., Amezquita, A., 2001. Visual signalling in anuran amphibians. In: Ryan, M. (Ed.), Frogs Speaking. Recent Advances in the Study of Anuran Communication. Smithsonian Institution Press, Washington, pp. 221-241.

Huelsenbeck, J.P., Ronquist, F., 2001. MrBayes: Bayesian inference of phylogenetic trees. Bioinformatics 17, 754-755.

Macey, J.R., Larson, A., Ananjeva, N.B., Fang, Z., Papenfuss, T.J., 1997. Two novel gene orders and the role of light-strand replication in rearrangement of the vertebrate mitochondrial genome. Mol. Biol. Evol. 14, 91-104.

Mausfeld, P., Vences, M., Schmitz, A., Veith, M., 2000. First data on the molecular phylogeography of scincid lizards of the genus Mabuya. Mol. Phylogenet. Evol. 17, 11-14.

Myers, N., Mittermeier, R.A., Mittermeier, C.G., de Fonseca, G.A.B., Kent, J., 2000. Biodiversity hotspots for conservation priorities. Nature 403, 853-858.

Odierna, G., Vences, M., Aprea, G., Lötters, S., Andreone, F., 2001. Chromosome data for Malagasy poison frogs (Amphibia: Ranidae: Mantella) and their bearing on taxonomy and phylogeny. Zool. Sci. $18,505-514$

Pintak, T., Vences, M., Glaw, F., Böhme, W., 1998. Comparative chromosome morphology of Malagasy poison frogs (Amphibia: Ranidae: Mantella). Folia Zool. 47, 197-204.

Posada, D., Crandall, K.A., 1998. Modeltest: testing the model of DNA substitution. Bioinformatics 14, 817-818.

Raxworthy, C.J., Nussbaum, R.A., 2000. Extinction and extinction vulnerability of amphibians and reptiles in Madagascar. Amph. Rept. Conserv. 2, 15-23.

Raymond, M., Rousset, F., 1995. An exact test for population differentiation. Evolution 49, 608-615.

Riberon, A., Miaud, C., Grossenbacher, H., Taberlet, P., 2001. Phylogeography of the Alpine salamander, Salamandra atra (Salamandridae) and the influence of the Pleistocene climatic oscillations on population divergence. Mol. Ecol. 10, 2555-2560.

Riberon, A., Sotiriou, E., Miaud, C., Andreone, F., Taberlet, P., 2002. Lack of genetic diversity in Salamandra lanzai revealed by cytochrome $b$ gene sequences. Copeia 2002, 229-232.

Schaefer, H.-C., Vences, M., Veith, M., 2002. Molecular phylogeny of Malagasy poison frogs, genus Mantella (Anura: Mantellidae): homoplastic evolution of colour pattern in aposematic amphibians. Org. Divers. Evol. 2, 97-105.

Schneider, S., Roessli, D., Excoffier, L., 2000. ARLEQUIN v. 2.000; A Software for Population Genetic Data Analysis. Genetics and Biometry Laboratory, University of Geneva, Switzerland.

Shimodaira, H., Hasegawa, M., 1999. Multiple comparison of loglikelihoods with applications to phylogenetic inference. Mol. Biol. Evol. 16, 1114-1116.

Sumida, M., Kaneda, H., Kato, Y., Kanamori, Y., Yonekawa, H., Nishioka, M., 2000. Sequence variation and structural conservation in the D-loop region and flanking genes of mitochondrial DNA from Japanese pond frogs. Genes Genet. Syst. 75, 79-92.

Sumida, M., Kanamori, Y., Kaneda, H., Kato, Y., Nishioka, M., Hasegawa, M., Yonekawa, H., 2001. Complete nucleotide sequence and gene rearrangement of the mitochondrial genome of the Japanese pond frog Rana nigromaculata. Genes Genet. Syst. 76 311-325.

Summers, K., Clough, M.E., 2001. The evolution of coloration and toxicity in the poison frog family (Dendrobatidae). Proc. Natl. Acad. Sci. USA 98, 6227-6232.

Swofford, D.L., Olsen, G.J., Waddell, P.J., Hillis, D.M., 1996. Phylogenetic inference. In: Hillis, D.M., Moritz, C., Mable, B.K. (Eds.), Molecular Systematics, second ed. Sinauer, Sunderland, pp. 407-514. 
Swofford, D.L., 2001. PAUP*. Phylogenetic Analysis Using Parsimony (*and other methods), version $4 \mathrm{~b} 8$. Sinauer, Sunderland, MA.

Tan, A.M., Wake, D.B., 1995. MtDNA phylogeography of the California newt, Taricha torosa (Caudata, Salamandridae). Mol. Phylogenet. Evol. 4, 383-394.

Tarkhnishvili, D., Thorpe, R.S., Arntzen, J.W., 2000. Pre-Pleistocene refugia and differentiation between populations of the Caucasian salamander (Mertensiella caucasica). Mol. Phylogenet. Evol. 14, 414-422.

Templeton, A.R., Crandall, K.A., Sing, C.F., 1992. A cladistic analysis of phenotypic associations with haplotypes inferred from restriction endonuclease mapping and DNA sequence data. III. Cladogram estimation. Genetics 132, 619-633.

Vallan, D., 2000. Influence of forest fragmentation on amphibian diversity in the nature reserve of Ambohitantely, highland Madagascar. Biol. Conserv. 96, 31-43.

Vallan, D., 2002. Effects of anthropogenic environmental changes on amphibian diversity in the rain forests of eastern Madagascar. J. Trop. Ecol. 18, 725-742.

Vences, M., Glaw, F., 2001. When molecules claim for taxonomic change: new proposals on the classification of Old World treefrogs. Spixiana 24, 85-92.

Vences, M., Glaw, F., Böhme, W., 1998a. Evolutionary correlates of microphagy in alkaloid-containing frogs (Amphibia: Anura). Zool. Anz. 236, 217-230.
Vences, M., Glaw, F., Mausfeld, P., Böhme, W., 1998b. Comparative osteology of Malagasy poison frogs of the genus Mantella (Amphibia: Ranidae: Mantellinae). Bonn. zool. Beitr. 48, 205-215.

Vences, M., Hille, A., Glaw, F., 1998c. Allozyme differentiation in the genus Mantella (Amphibia: Anura: Mantellinae). Folia Zool. 47, 261-274.

Vences, M., Glaw, F., Böhme, W., 1999. A review of the genus Mantella (Anura, Ranidae, Mantellinae): taxonomy, distribution and conservation of Malagasy poison frogs. Alytes 17, 3-72.

Vences, M., Kosuch, J., Lötters, S., Widmer, A., Köhler, J., Jungfer, K.H., Veith, M., 2000. Phylogeny and classification of poison frogs (Amphibia: Dendrobatidae), based on mitochondrial 16S and 12S ribosomal RNA gene sequences. Mol. Phylogenet. Evol. 15, 34-40.

Vidal-Romaní, J.R., Ramanhison, H., Rabenandrasana, S., 1997. Geomorphologie granitique du Massif de l'Andringitra: sa relation avec l'evolution de l'Ile pendant le Cenozoique. Cadernos do Laboratorio Xeoloxico de Laxe 22, 183-208.

Yoder, A.D., Irwin, J.A., Payseur, B.A., 2001. Failure of the ILD to determine data combinability for slow loris phylogeny. Syst. Biol. $50,408-424$.

Zimmermann, H., Hetz, P., 1992. Vorläufige Bestandsaufnahme und Kartierung des gefährdeten Goldfröschchen, Mantella aurantiaca, im tropischen Regenwald Ost-Madagaskars. Herpetofauna 14, 33 34.

Zimmermann, H., 1996. Der Schutz des tropischen Regenwaldes und ein kleines Fröschchen in Ost-Madagaskar. Stapfia 47, 189-218. 